\title{
THE USE OF CARROL-GIRRARD T -BAR SCREW FOR REDUCTION OF ZYGOMATICO-MAXILLARY FRACTURE BY TWO DIFFERENT ORBITAL APPROACHES (A RANDOMIZED CONTROLLED CLINICAL TRIAL)
}

\author{
Mohamed Shokry* and Lydia Nabil ${ }^{*}$
}

\begin{abstract}
Aim: This study aimed to evaluate two different approaches; subtarsal and transconjunctival approaches for reduction and fixation of ZMC fractures with the aid of Carrol-Girrard T -bar screw regarding the accessibility to the surgical site, adequacy of reduction and incidence of postoperative complications.

Materials and Method: Twenty patients suffering from zygomatico- maxillary complex fracture (ZMC) were selected conveniently and randomly divided into two equal groups. Transconjunctival incision was used for accessing the fractured ZMC in the study group, while the subtarsal approach was used in the control group. The reduction and fixation in both groups was achieved using the Carrol-Girrard T bar screw.
\end{abstract}

Results: No statistically significant difference was seen among both groups in terms of postoperative pain, edema, ocular or sensory complications and adequacy of ZMC reduction.

Conclusion: Transconjunctival incision for the exposure of the infraorbital rim and orbital floor combined with the use of Carroll-Girrard T- bar screw for the reduction and management of ZMC fracture is a convenient approach with minimal reported intra or postoperative complications.

KEYWORDS, Carroll-Girrard T- bar, ZMC fracture, Transconjunctival incision, Subtarsal incisio

\section{INTRODUCTION}

The zygomatic and maxillary bones give the face its shape and proper symmetry. They are the second most frequently broken site within the orofacial region after the nasal bone due to their morphologic prominence. ${ }^{(1)}$ The etiology of zygomatic Maxillary complex (ZMC) fractures includes road traffic crashes, attacks, falls, sports, and gunshot injuries. (2-5) It accounts for approximately $42 \%$ of all facial fractures and $64 \%$ of all middle third fractures. ${ }^{(6)}$

Improper diagnosis and treatment of these injuries can lead to esthetic and functional

\footnotetext{
* Associate Professor, Oral and Maxillofacial Surgery, Faculty of Dentistry, Alexandria University
} 
problems..$^{(7)}$ Enophthalmos, diplopia, rotating zygomatic dislocation, orbital dystopia, and midface broadening may all occur if the horizontal and vertical pillars of the ZMC are not properly aligned; these conditions are difficult to correct by secondary revision surgery. ${ }^{(8)}$

Therefore, maxillofacial surgeons face a difficult task when it comes to treating ZMC fractures. Several methods and surgical incisions have been identified for treating zygomatic complex fractures where fracture stability is a major concern. ${ }^{(9)}$

All treatments aim for a precise three-dimensional (3-D) reconstruction of the damaged anatomy. A variety of surgical procedures have been used to expose zygomatic fractures, including intraoral (Keen), temporal (Gillies), infraorbital, lower eyelid, subciliary, subtarsal, and transconjunctival approaches. Bone clamps, towel clips, hemostats, and several elevators were used for reduction and fixation. ${ }^{(10)}$

A complication profile is usually encountered in all lower eyelid incisions including the subciliary, subtarsal and infraorbital incisions. The aesthetic and functional importance of lower lid malposition deformities varies significantly. Entropion, lower lid retraction, scleral show, and ectropion are the most common malposition deformities. ${ }^{(11)}$

Since orbital fractures are usually associated with some or all the zygomatic articulations (zygomaticofrontal, zygomatico-sphenoid, zygomaticotemporal, and zygomatico-maxillary) reduction of ZMC fracture is complicated, unreliable, and impossible to sustain with most of the conventional used techniques ${ }^{(12-14)}$

The transconjunctival approach became more popular throughout the previous years for gaining access to ZMC fractures. The main advantages are the unseen incision line, low risk of ectropion, and better accessibility when compared to other cutaneous approaches. When it is used as a way for
ZMC exposure together with lateral canthotomy; the infra-orbital rim, floor of the orbit and the fronto-zygomatic suture are obviously seen without any skin incisions. ${ }^{(15-19)}$

The usage of the Carroll-Girard T-bar screw resolves these problems through allowing an accurate handling and reduction of ZMC fractures. A total regulation of the displaced bone is feasible because the T-bar screw is securely attached to the zygomatic bone and the screw is gripped as a handle enables precise three-dimensional positioning of the fractured zygoma. Instruments such as a Dingman elevator, Rowe elevator, or bone hook inserted underneath the $\mathrm{ZMC}$ are unable to provide this level of control. ${ }^{(20,21)}$

Nocertain approach of ZMC fracture management is ideal regarding esthetic outcome, adequate exposure of the surgical site and prevention of postoperative complications. Therefore, the aim of this study was to evaluate two different approaches; subtarsal and transconjunctival approaches for reduction and fixation of ZMC fractures with CarrolGirrard $\mathrm{T}$ bar screw in relation to accessibility to the surgical site, adequacy of reduction and incidence of postoperative complications.

\section{MATERIALS AND METHOD}

\section{Study design}

This study was carried out as a parallel, controlled, randomized clinical trial.

\section{Study setting}

Patients with ZMC fractures who required open reduction and internal fixation were recruited from those admitted to the emergency room of Alexandria University Hospital. All patients signed an informed consent, and the study was approved by the ethics committee of the Faculty of Dentistry, Alexandria University. 


\section{Sample size and enrollment of the patients}

The estimated sample size was calculated according to http://epitools.ausvet.com.au/, by taking the mean zygomatic bone height from previous similar study conducted by Furst et al ${ }^{(22)}$, where the means $+(\mathrm{SD})$ were $89.76(+5.84)$ and $92.3(+4.59)$, and the variance was calculated to be 13.2. Assuming the confidence level of $95 \%$ and a study power of $80 \%$, the calculated sample size was estimated as 18 participants. Ten percent was added to the sample size to eliminate the possibility of drop-out throughout the clinical trial. Therefore, a total number of 20 patients were selected to contribute to this study.

The twenty patients were selected according to the following inclusion criteria; patients that were medically fit and free from any condition contraindicating surgery and those who suffered from displaced zygomatico-maxillary complex fractures as evidenced radiographically. On the other hand, patients complaining from systemic diseases, suffered from comminuted zygomatico-maxillary complex fractures, old zygomatico-maxillary complex fractures, infection at the fracture site, comminuted fractures, the presence of lacerations at the surgical site and bilateral zygomatico-maxillary complex fractures were excluded from this study.

The selected twenty patients were allocated randomly using a randomization generated table with the aid of the randomizer.org website into two equal groups, each consisted of ten patients. The first group (study group) consisted of 10 patients in whom the transconjunctival approach was used to access the fracture site and the second group (control group) consisted of 10 patients in whom the subtarsal approach was used to access the fracture site. In both groups, the Carroll-Girard T-bar screw was used to reduce the fractured ZMC.

After preoperative clinical and radiographic assessment of the patients, patients were randomly allocated to either group. Operations were performed under general anesthesia in the Oral and Maxillofacial surgery Department, Faculty of Dentistry, Alexandria University.

In group I (study group), the globe was protected by a corneal shield. Two or three traction sutures were placed from palpebral conjunctiva to skin, about 4 to $5 \mathrm{~mm}$ below the lid edge, and the lower eyelid was everted with fine forceps. Lateral canthotomy was done if required. The transconjunctival incision was performed through retroseptal approach. The orbital fat was constrained by a wide retractor positioned slightly posterior to the infraorbital margin. The periosteum along the orbital rim, anterior surface of the maxilla, zygoma, and orbital floor was stripped using periosteal elevators, exposing the fracture site. (Fig 1a,1b)

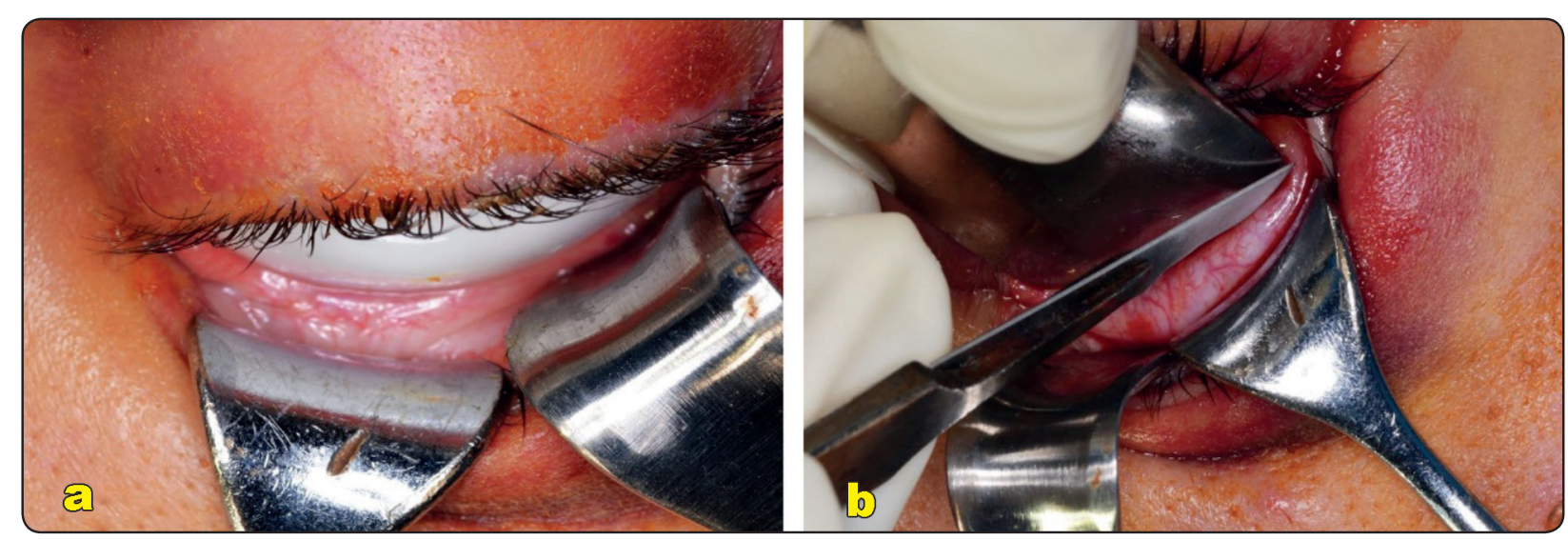

Fig. (1): a- corneal shield in place before transconjunctival incision. b- transconjunctival incision 
In group II (control group), temporary tarsorrhaphy was utilized and removed when the procedure was completed. A subtarsal incision was made down the whole length of the lid, approximately 4-5 $\mathrm{mm}$ inferior to the lashes. The initial incision was made entirely through the skin. For a few millimeters, subcutaneous dissection toward the inferior orbital rim was carried out. The orbicularis oculi muscle was incised and then a scalpel was used to make an incision into the periosteum on the front surface of the maxilla and zygoma, 2 to $3 \mathrm{~mm}$ below the orbital rim. Periosteal elevators were then employed to separate the periosteum from the underlying osseous skeleton along the maxilla and zygoma's front surfaces, as well as inside the orbit.

The fracture was subsequently reduced using a custom-made Carroll-Girrard T- bar screw in both groups; the malar eminence was exposed, the bone was pierced using a perforating drill $(2 \mathrm{~mm})$, and the Carroll-Girrard T-bar screw was $2.5 \mathrm{~mm}$ thick. The Carroll-Girard T-bar screw was penetrated through the drilled hole and rotated in a clockwise direction until it is firmly placed within the bone, usually at a depth of $10 \mathrm{~mm} .{ }^{(20)}$ The zygoma was moved in the desired direction, and the bone was reduced to its proper anatomic location. The zygomatic-complex was then holed in position with the Carroll-Girard T-bar screw and fixation was done using titanium miniplates and screws. (Fig $2 \mathrm{a}, 2 \mathrm{~b}$ )
After proper hemostasis, in the study group, the conjunctiva was closed with a running 6-0 vicryl suture (Vicryl - Ethicon, Johnson \& Johnson). In the control group, the wound was closed in layers 4-0 vicryl for periosteum/muscle and 6-0 polyprolene (Prolene - Ethicon, Johnson \& Johnson) for skin closure.

\section{Postoperative care}

All patients were instructed to apply ice packs extra-orally for the first day. The following medications were prescribed: Cefotax (cefotaxime, manufactured by E.I.P.I.C.O.) 1 gm/12 hours intravenous for the first day followed by Augmentin (Amoxicillin $875 \mathrm{mg}+$ Clavulanic acid $125 \mathrm{mg}$ : GlaxoSmithKline, UK) 1 gm orally twice daily for the next 5 days; Alpha chemo-trypsin ampoules (Leurquin France, packed by Amoun pharmaceutical CO.S.A.E-Egypt) as anti-edematous once daily for 5 days; and Cataflam ( Diclofenac potassium 50mg: Novartis-Switzerland) every eight hours for 5 days.

The two groups were compared using a detailed follow-up after 24 hours, one week, four weeks, six weeks, and three months to measure the following parameters: accessibility to the surgical site, postoperative edema, postoperative pain using a 10-point VAS, postoperative scar (as evident or non-evident), sensory nerve function by both subjective evaluation and objective assessment

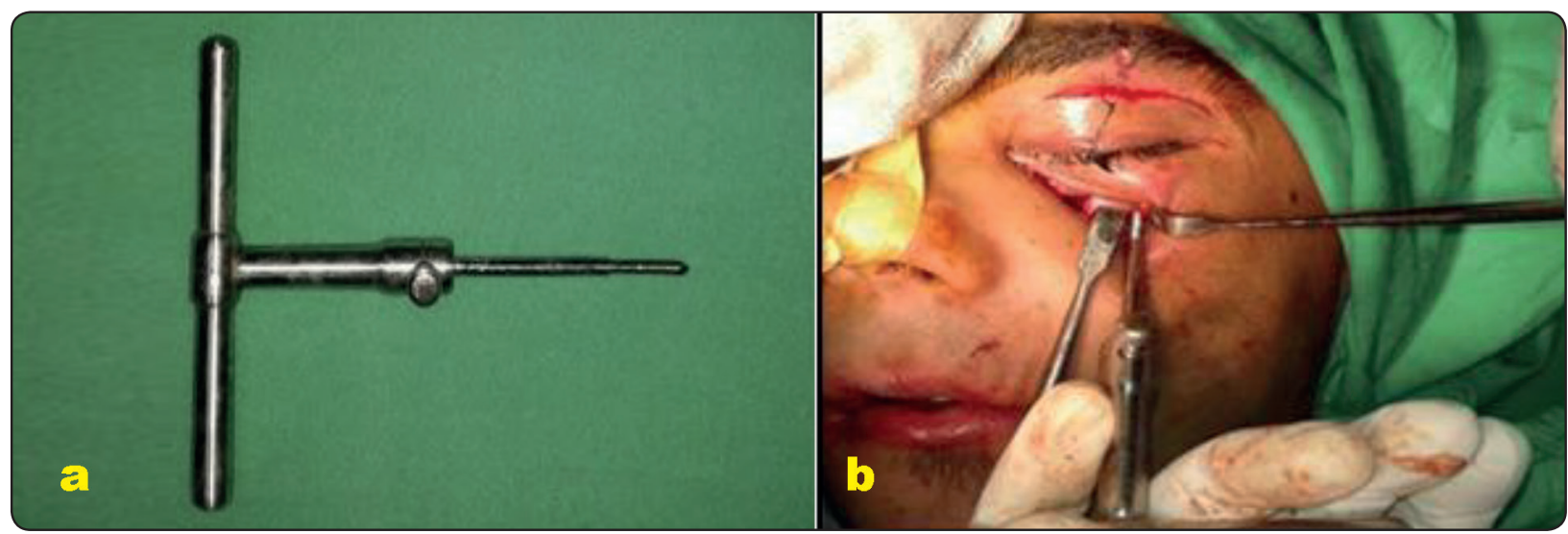

Fig. (2a): Custom -made Carrol Girrard T- bar screw. Fig. (2b): The carroll-girard T-bar screw introduced into zygomatic buttress. 
along distribution of the infraorbital nerve and postoperative ocular complications as ectropion, entropion, enophthalmos, disturbed eye movements and scleral show. Postoperative radiographic evaluation using computed tomography was done to assess the adequacy of fracture reduction, compare zygomatic projection and zygomatic height before and after surgery in both groups. (Table 1)

The axial cut of the CT scan of the complex was used to assess the Zygomatic-complex projection. The width of the anterior and posterior zygomatic complexes was measured (measure 1 and 2, respectively), and the distance between these two sites was used to calculate the zygomatic-complex projection (measure 3). (Fig.3a). To calculate the $\mathrm{ZCP}$ of the fractured side relative to the normal side, these measurements were taken on both the normal and fractured sides.

Moreover, the distance between the horizontal reference line and the point at the most lateral aspect of the curved surface of the complex is zygomaticcomplex height, which was measured using a coronal slice of the CT scan of the complex (measure 4). (Fig.3b). To calculate the $\mathrm{ZCH}$ of the fractured side relative to the normal side, these measurements were taken on both the normal and fractured sides.

TABLE (1): Description of Reference Lines, Landmarks and Measurements

\begin{tabular}{|c|c|}
\hline Reference line or measurement & Anatomic Description \\
\hline $\begin{array}{l}\text { Axial midline } \\
\text { (Figure 3a) }\end{array}$ & $\begin{array}{l}\text { Axial measurement was made from a line perpendicular to an imaginary sagittal line } \\
\text { drawn posteriorly from vertical plate of ethmoid anteriorly to the midline of the clivus } \\
\text { on the skull base or the midline of the foramen magnum (which was most easily } \\
\text { identified). }\end{array}$ \\
\hline $\begin{array}{l}\text { Measurement } 1 \\
\text { (Figure 3a) } \\
\text { (Posterior zygomatic complex width) }\end{array}$ & $\begin{array}{l}\text { The grid was aligned to the axial midline. Measurement } 1 \text { was the measurement of the } \\
\text { distance from the midline to the most lateral aspect of the curve of the zygomatic arch. }\end{array}$ \\
\hline $\begin{array}{l}\text { Measurement } 2 \text { (Figure 3a) } \\
\text { (Anterior zygomatic complex width) }\end{array}$ & $\begin{array}{l}\text { The grid was aligned to the axial midline and a point was marked on the most } \\
\text { anterolateral aspect of the zygomatic complex. This point was established by the } \\
\text { intersection of a line perpendicular to the axial midline extending laterally and through } \\
\text { the most anterior portion of the zygomatic arch and a line parallel to the axial midline } \\
\text { extending anterior from the most lateral aspect of the zygomatic arch. A bisecting } \\
\text { line from the intersection of these two lines was drawn to the outer surface of the } \\
\text { zygomatic arch. Measurement } 2 \text { was the measurement of the distance from the midline } \\
\text { to this point }\end{array}$ \\
\hline $\begin{array}{l}\text { Measurement } 3 \\
\text { (Figure } 3 \mathrm{a}) \\
\text { (Zygomatic complex projection) }\end{array}$ & $\begin{array}{l}\text { The distance between the two points established on the zygomatic arch for } \\
\text { measurements } 1 \text { and } 2 \text { is measurement } 3 \text {. }\end{array}$ \\
\hline $\begin{array}{l}\text { Coronal midline and reference } \\
\text { Line (Figure } 3 b)\end{array}$ & $\begin{array}{l}\text { The grid was aligned to a midline through the most superior aspect of the suture } \\
\text { joining the nasal bones and the midline crest of the maxilla. A second line, } \\
\text { perpendicular to the first, was aligned on the grid through the most superior aspect of } \\
\text { the superior orbital rims. This was referred Measurement } 4 \text {. }\end{array}$ \\
\hline $\begin{array}{l}\text { Measurement } 4 \\
\quad \text { (Figure } 3 b) \\
\text { (Zygomatic complex height) }\end{array}$ & $\begin{array}{l}\text { Using the grid, the most lateral aspect of the curved surface of the zygomatic } \\
\text { complex was identified. Measurement } 4 \text { was the measurement of the distance } \\
\text { between the horizontal reference line and the point of the zygomatic complex. }\end{array}$ \\
\hline
\end{tabular}




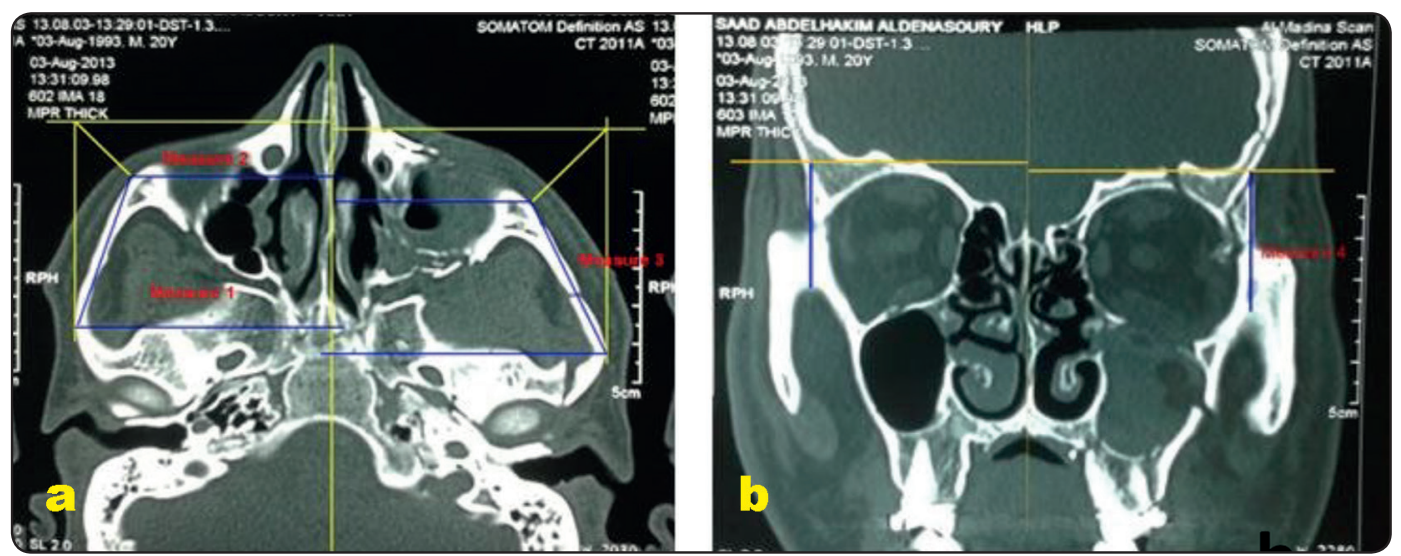

Fig. (3 a): Zygomatic projection measurements- Fig. (3b): Zygomatic height measurements.

All collected data was tabulated and statistically analyzed using IBM Statistical Package for Social Science (SPSS) software version 23.0

\section{RESULTS}

The study was conducted on 20 patients including 12 males and 8 females, their age ranging from 35 to 50 years, with mean age $38.56 \pm 9.07$ years. The etiological factors of trauma were road traffic accidents in 12 patients, interpersonal violence in 3 patients and falling in 5 patients.

\section{Pain}

The mean pain intensity in group 1 was $6.70 \pm 1.16$ at 24 hours, $3.60 \pm 0.966$ after 1 week and $1.70 \pm 0.675$ after 2 weeks. The mean pain intensity in group 2 was $6.60 \pm 1.43$ at 24 hours, $3.80 \pm 1.135$ after 1 week and $1.80 \pm 0.632$ after 2 weeks. Pain intensity was reduced significantly within each group from 24 hours to 2 weeks $(\mathrm{p}<0.05)$. The difference between the 2 groups was statistically non-significant at the different time periods ( $p>0.05$ ). (Fig 4)

\section{Edema}

Edema was significantly reduced within each group across the follow up period while the difference between the two groups was non-significant during the different time periods ( $>00.05$ ). (Fig 5)

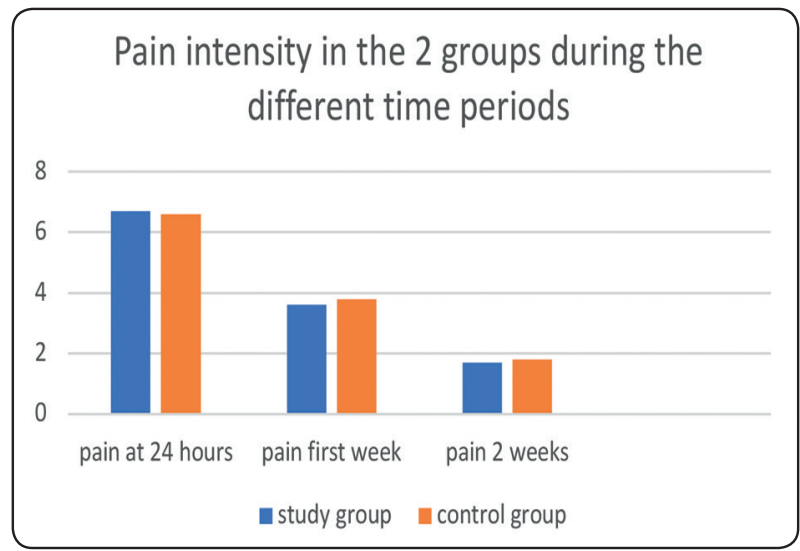

Fig. (4): Pain intensity in the 2 groups at 24 hours, 1 week and 2 weeks.

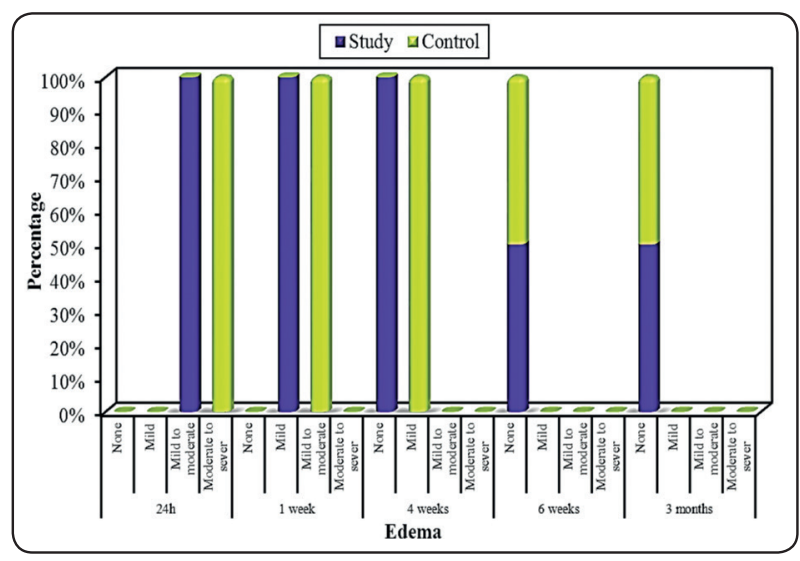

Fig. (5): Edema within the 2 groups during the different time periods. 
TABLE (2): Comparison between the two studied groups according to ocular complications, wound healing, sensory nerve function and scar at $4 \mathrm{w}$.

\begin{tabular}{|c|c|c|c|c|c|c|}
\hline & \multicolumn{2}{|c|}{$\begin{array}{c}\text { Study } \\
(\mathbf{n}=\mathbf{1 0})\end{array}$} & \multicolumn{2}{|c|}{$\begin{array}{l}\text { Control } \\
(n=10)\end{array}$} & \multirow{2}{*}{$\chi^{2}$} & \multirow[t]{2}{*}{${ }^{\mathrm{FE}} \mathbf{p}$} \\
\hline & No. & $\%$ & No. & $\%$ & & \\
\hline \multicolumn{5}{|c|}{ Ocular complications } & \multirow{3}{*}{0.282} & \multirow{3}{*}{0.763} \\
\hline No & 8 & 80.0 & 9 & 90.0 & & \\
\hline Yes & 2 & 20.0 & 1 & 10.0 & & \\
\hline \multicolumn{5}{|l|}{ Wound healing } & \multirow{3}{*}{2.288} & \multirow{3}{*}{0.456} \\
\hline Normal & 9 & 90.0 & 8 & 80.0 & & \\
\hline Disturbed & 1 & 10.0 & 2 & 20.0 & & \\
\hline \multicolumn{5}{|c|}{ Sensory nerve function } & \multirow{3}{*}{2.284} & \multirow{3}{*}{0.321} \\
\hline Not affected & 8 & 80.0 & 9 & 90.0 & & \\
\hline Affected & 2 & 20.0 & 1 & 10.0 & & \\
\hline \multicolumn{5}{|l|}{ Scar at 6w } & \multirow{3}{*}{$12.000^{*}$} & \multirow{3}{*}{$<0.001^{*}$} \\
\hline No & 10 & 100.0 & 9 & 90.0 & & \\
\hline Yes & 0 & 0.0 & 1 & 10.0 & & \\
\hline
\end{tabular}

c2: Chi square test

FE: Fisher Exact

p: $p$ value for comparing between the two groups

*: Statistically significant at $p \leq 0.05$

\section{Postoperative complications:}

In terms of ocular problems, wound healing, and sensory nerve function, there was no statistical significance between the two groups throughout the entire postoperative follow-up period $(p>0.05$ ). In terms of scarring and aesthetic appearance, statistical significance was found in both groups over the entire surgical follow-up period $(\mathrm{p}<0.05)$.

(Table 2)

\section{Zygomatic complex projection:}

The mean zygomatic complex projection in group 1 before surgery was $69.176 \pm 10.372$, while it was $79.907 \pm 8.729$ in group 2 before surgery and the difference between the two groups was statistically significant $(\mathrm{p}=0.022)$. The mean zygomatic complex projection in group 1 after surgery was $84.476 \pm 8.852$, while it was $89.501 \pm 5.326$ in group
2 after surgery and the difference between the two groups was statistically non-significant $(\mathrm{p}=0.145)$. The difference between the presurgical and the postsurgical zygomatic complex projection within each group was statistically significant $(\mathrm{p}<0.05)$. (Fig. 6)

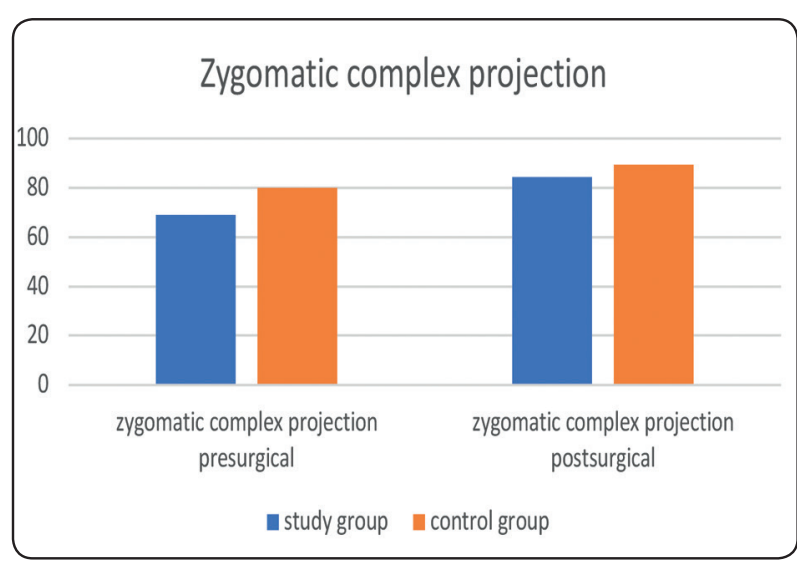

Fig. (6): Zygomatic complex projection in both groups before and after surgery. 


\section{Zygomatic complex height:}

The zygomatic complex height was $84.463 \pm 4.376$ in group 1 before surgery, while it was 88.876 \pm 4.033 in group 2 before surgery. The difference between the two groups was statistically significant $(\mathrm{p}=0.031)$. The zygomatic complex height was $92.575 \pm 2.859$ in group 1 after surgery, while it was $94.638 \pm 3.145$ in group 2 after surgery. The difference between the two groups was statistically non-significant $(\mathrm{p}=0.142)$. The difference between the presurgical and postsurgical zygomatic complex height was statistically significant within each group



Fig. (7): Zygomatic complex height in the 2 groups before and after surgery $(\mathrm{p}<0.05)$. (Fig 7-9)



Fig. (8) a: Preoperative coronal CT scan (study group) Showing left blow out fracture with orital fat herniation. b: Postoperative 3D CT scan in study group showing reduction and fixation using titanium miniplates and screws.

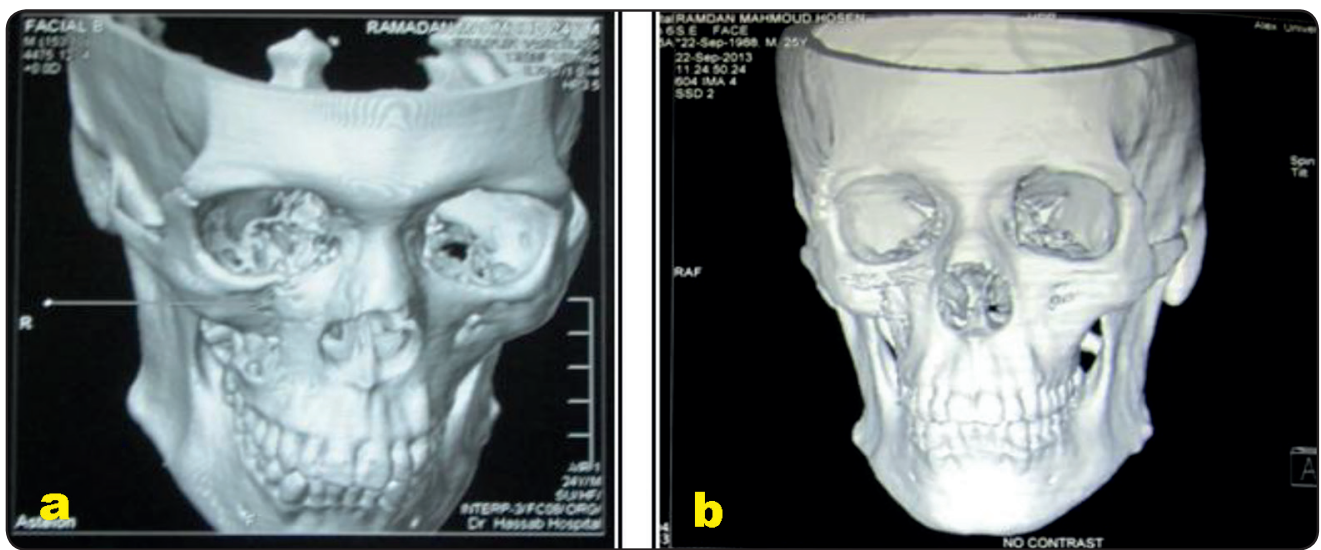

Fig. (9): Three dimensional CT scans of patient (control group) before (a) and after surgery (b). 


\section{DISCUSSION}

The ZMC serves as a functional and aesthetic unit within the facial skeleton. The orbital contents are separated from the maxillary sinus and temporal fossa by this complex, which acts as a bone barrier. ZMC fractures are also referred to as tetrapod fractures because the zygoma has four bony attachments to the skull. ${ }^{(23)}$

Because of the structure of bone, mid-face injuries heal quickly and solidify earlier than other bones. To achieve cosmetic and functional results, early intervention is required. Various approaches for ZMC repair have been promoted, with a focus on distinct reduction and fixing procedures. The goal of any treatment is to achieve the best results while causing the least amount of morbidity. ${ }^{(24)}$

For the surgical treatment of ZMC fractures, four key principles should be followed. Enough exposure is essential to achieve appropriate reduction and stable fixation with the fewest problems. Because open reduction with internal fixation can offer a stable reduction and fixation while also increasing bone healing and shortening treatment times, it has become the standard of care. ${ }^{(25)}$

The transconjunctival method was shown to be superior to its transcutaneous counterparts by a number of publications. Bourquet first proposed this method for removing herniated orbital fat. In ophthalmology, otorhinolaryngology, and maxillofacial surgery, this procedure is used where it is also known as the inferior fornix approach. ${ }^{(26,27)}$

Road Traffic Accidents (RTA) are the most common cause of maxillofacial fractures worldwide, especially in developing nations, according to several authors. This coincides with our results, which is most probably explained by irresponsible driving, and lack of enforcement of road safety standards. ${ }^{(28)}$

There were no infections, hematomas, other globe complications in either the study or control groups during the follow-up period. This could indicate that there was no negative impact on the globe when the transconjunctival technique was used.

In terms of postoperative sensory nerve function, the study group's cases all exhibited normal objective and subjective infraorbital nerve function. The control group, on the other hand, had two incidences of transitory nerve affection, with patients reporting paresthesia in the cheek area. By the end of the follow-up period, both cases had restored their normal sensation.

The difference between the groups was statistically insignificant, which could be justified as the state of nerve compression and affection is a preoperative parameter that is determined by the accuracy of the reduction and freeing the nerve from the compressing fractured segments, not by the type of approach used.

In terms of ocular problems, there was no statistically significant difference between the two groups over the entire follow-up period. Two cases in the transconjunctival group revealed minor temporary entropion, which is a frequent eyelid malposition in which the eyelid edge curls inwards.

Entropion can be caused by a variety of causes, including the type of damage and surgical method. The site of the incision, the device utilized for the incision (cautery or blade), the dissection, and the closure technique all act as risk factors for entropion development in the transconjunctival approach. Over a ten-year span, Ridgway et al documented just two incidences of entropion with the transconjunctival technique. They concluded that the severe traction and lack of surgical field exposure were the most likely causes of entropion. ${ }^{(29)}$

A case from the control group complained from ectropion and scleral show which are symptoms of an improperly positioned eyelid. Ectropion is defined as the eversion of the lower eyelid edge, which exposes the globe to more light and causes it to dry out. Loss of 
muscle tone, aberrant cicatricial connection between the orbicularis oculi and the surrounding structures, or scar contracture, according to Rohrich et al (2003), may result in postoperative ectropion and scleral show. ${ }^{(30)}$

The sub-tarsal incision in the control group, although being put in the skin crease, revealed a visible healing mark during the follow-up period. Obviously, the transconjunctival technique did not cause this, and the difference between the groups was statistically significant.

During the therapy of ZMC fractures, the transconjunctival technique is a very convenient and aesthetic way to expose the infraorbital rim and orbital floor with low rate of postoperative complications. On the other hand, this approach is extremely techniquesensitive and necessitates good surgical experience.

In our work, we employed linear measurements on the axial and coronal pre and postoperative CT cuts to calculate zygomatic complex projection and zygomatic complex height to assess zygomatic complex symmetry. The findings of the statistical analysis revealed no significant differences between the two groups after surgery.

Finally, the non-significant difference between both groups using Carroll-Girrard T -bar screw for reduction of ZMC confirms that optimal esthetics can never be reached only by a single technique but by different techniques according to each case.

\section{CONCLUSION}

Form the results of this study we may point out that the utilization of the transconjunctival approach for the exposure of the infraorbital rim and orbital floor combined with the use of Carroll-Girrard $\mathrm{T}$ bar screw for the reduction and management of ZMC fracture is a convenient approach with minimal reported intra or postoperative complications. Carroll-Girard T-bar Screw instrument is simple to use and accurate during reduction and fixation of $\mathrm{ZMC}$ fractures and it can rotate to any direction and vector.

\section{REFERENCES}

1- Meslemani D, Kellman R. Zygomaticomaxillary complex fractures. Arch Facial Plast Surg 2012; 14: 62-66.

2- Banks P, Brown A. Fractures of the facial skeleton. $1^{\text {st }}$ ed Oxford: Wright; 2001.P. 40-155.

3- Klenk G, Kovacs A. Etiology and pattern of facial fractures in the United Arab Emirates. J Craniofac Surg 2003; 14: 78-84.

4- Adebayo E, Ajike O, Adekeye E. Analysis of the pattern of maxillofacial fractures in Kaduna, Nigera. Br J Oral Maxillofac Surg 2003; 41: 396-400.

5- Motamedi M. An assessment of maxillofacial fractures: a five-year study of 237 patients. J Oral Maxillofac Surg 2003; 61: 61-4.

6- Kaastad E, Freng A. Zygomatic-maxillary fractures. Late results after traction-hook reduction. J Craniomaxillofac Surg 1989; 17: 210-14.

7- Peretti N, MacLeod S. Zygomaticomaxillary complex fractures: diagnosis and treatment. Current opinion in otolaryngology \& head and neck surgery. 2017 Aug $1 ; 25(4): 314-9$

8- Eftekhari SS, Bui T, Grau Jr MJ, Krishnan DG. Management of zygomaticomaxillary complex and orbital fractures. Oral and Maxillofacial Surgical Secrets-E-Book. 2015 Oct 15:329.

9- Ellis E, Kittidumkerng W. Analysis of treatment for isolated zygomaticomaxillary complex fractures. Journal of oral and maxillofacial surgery. 1996 Apr 1;54(4):386-400 .

10- Zingg M, Laedrach K, Chen J, Chowdhury K, Vuillemin T, Sutter F, Raveh J. Classification and treatment of zygomatic fractures: a review of 1,025 cases. Journal of oral and maxillofacial surgery. 1992 Aug 1;50(8):778-90.

11- Raschke GF, Rieger UM, Bader RD, Schaefer O, Guentsch A, Hagemeister C, Schultze-Mosgau S. The zygomaticomaxillary complex fracture-an anthropometric appraisal of surgical outcomes. Journal of CranioMaxillofacial Surgery. 2013 Jun 1;41(4):331-7.

12- Rohrich R, Janis J, Adams W. Subciliary versus subtarsal approaches to orbitozygomatic fractures. Plast Reconstr Surg 2003; 111: 1708-14.

13- Hollier L, Thornton J, Pazmino P. The management of orbitozygomatic fractures. Plast Reconstr Surg 2003; 111: 2386-92. 
14- Chang E, Hatton M, Bernardino C, Rubin P. Simplified repair of zygomatic fractures through a transconjunctival approach. Ophthalmology 2005; 112: 1302-09

15- Patel PC, Sobota BT, Patel NM, Greene JS, Millman B. Comparison of transconjunctival versus subciliary approaches for orbital fractures: A review of 60 cases. J Craniomaxillofac Trauma 1998;4:17-21.

16- Jacono AA, Moskowitz B. Transconjunctival versus transcutaneous approach to upper and lower blepharoplasty. Facial Plast Surg. 2001;17:21-8.

17- Kelley P, Crawford M, Higuera S, Hollier LH. Two hundred ninety-four consecutive facial fractures in an urban trauma center: Lessons learned. Plast Reconstr Surg. 2005;116:42e$9 \mathrm{e}$.

18- Westfall CT, Shore JW, Nunery WR, Hawes MJ, Yaremchuk MJ. Operative complications of the transconjunctival inferior fornix approach. Ophthalmology 1991;98:1525-8.

19- Mullins JB, Holds JB, Branham G, Thomas JR. Complications of the transconjunctival approach: A review of 400 cases. Arch Otolaryngol Head Neck Surg 1997;123:385-8.

20- Baek J, Chung C, Hong I. Reduction of zygomatic fractures using the Carroll-Girard T-bar Screw. Arch Plast Surg 2012; 39: 556-60.

21- Ellis E $3^{\text {rd }}$, Kittidumkerng W. Analysis of treatment for isolated zygomaticomaxillary complex fractures. J Oral Maxillofac Surg 1996; 54: 386-400.

22- Furst I, Austin P, Paraoh M. The use of computed tomography to define zygomatic complex position. J Oral Maxillofac Surg 2001; 59: 647-54.
23- Gomes P, Passeri L, Barbosa J. A 5-year retrospective study of zygomatico-orbital complex and zygomatic arch fractures in Sa o Paulo State. J Oral Maxillofac Surg 2006; 64: 63-7.

24- Lakshmi N, Vivekanand S, Amit V, Srinivas C. Prospective blind comparative clinical study of two point fixation of zygomatic complex fracture using wire and mini plates. Head Face Med 2012; 8: 7.

25- Moreno EF, Vasconcelos BC, Carneiro SC, et al. Evaluation of fixation techniques with titanium plates and Kirschner wires for zygoma fractures: preliminary study. J Oral Maxillofac Surg 2012;70:2386-93.

26- Bourquet JN. Treatment chirurgical de poches sous les yeux sans cicatrice. Arch Prov Chir Fr Belg Chir 1928;31:433-7.

27- Tessier P. The conjunctival approach to the orbital floor and maxilla in congenital malformation and trauma. J Maxillofac Surg 1973;1:3-8.

28- Kurita M, Okazaki M, Ozaki M, Tanaka Y, Tsuji N, Takushima A,Harii K. Patient satisfaction after open reduction and internal fixation of zygomatic bone fractures. J Craniofac Surg 2010;21:45-9.

29- Ridgway EB, Chen C, Lee BT. Acquired entropion associated with the transconjunctival incision for facial fracture management. J Craniofac Surg. 2009;20(5):1412-5.

30- Rohrich RJ, Janis JE, Adams WP JR. Subciliary versus subtarsal approaches to orbitozygomatic fractures. Plast Reconstr Surg. 2003 15;111(5):1708-14. 